\title{
Economic evaluation of small wind turbines and hybrid systems for residential use
}

\author{
Mihail Predescu ${ }^{*}$ \\ Aeolus Energy International, Bucharest, Romania
}

\begin{abstract}
Renewable electricity generating systems are gaining ground in residential sector for the purpose of diminishing the electricity bills or to reaching some degree of energy independence. The decision to invest in small wind turbines or hybrid energy generation technologies should be based on an economic estimation of money invested in such systems. Levelized Cost of Energy (LCOE) calculation for local technologies of choice for residential energy generation is a very meaningful figure for deciding whether the investment can bring financial satisfaction and for selecting which type of technology is the best suited for a specific location.
\end{abstract}

\section{Introduction}

Renewable energy conversion technologies are becoming more and more popular in local energy generation for residences, contributing to distributed energy production, which is a new strategy in power generation. Conventional energy resources are becoming scarce in Europe and should be imported from abroad creating uncomfortable dependency and high degree of unpredictability of availability and prices.

Cleaner energy production is another hot topic at world level which determined the policy makers to promote legislation for boosting the renewable energy technologies penetration. Government incentives, either investment subsidies or feed-in tariff; however, disputed and unreliable they are, could be good reasons for deciding an investment in small wind or other renewable energy technology. Small wind turbines, photovoltaic or hybrid energy generating systems are currently the common options for residential applications, both on-grid and offgrid, since the primary resources are ready available at the very location. Technology selection and final decision should be based on economic assessment of the investment, otherwise the financial result could be far from expectations.

\section{Small wind turbine market}

Wind conversion technology is growing fast at world scale, registering two digits grows rate, and the prediction is to reach $800 \mathrm{GW}$ in 2020 and $2000 \mathrm{GW}$ by 2030. The economic aspects of investment in utility scale wind technology are well investigated for the reason that it is a huge industry requiring large amount of money for which accurate predictions are mandatory for minimizing the investment risks.

Small wind turbines are addressing individuals or small consumers at residential level. This industry is growing fast too. At the end of 2012 the cumulative figure of installed small wind systems was more than 806,000 units worldwide [1], which means a $10 \%$ increases compared to the previous year.

Economic evaluation of small wind systems is not quite well addressed yet for two reasons: the investment is much smaller than large wind systems and variability of the wind conditions at a potential site requests a specific approach. Additionally, the specific cost of small wind turbines systems on the market is highly variable, depending on producers, quality of components, installation costs and other local costs, but depends heavily on financial possibilities of potential investors.

\section{Method of computing LCOE}

Computation of Levelized Cost of Energy (LCOE) is the common method for estimation and comparison of investment performance in alternative energy generation technologies [2]. Basically, LCOE is a prediction of the specific energy production cost (e.g. $€ / \mathrm{kWh})$, as constant value of income/saving over a period of operation, usually lifetime, expressed in present value of money. The general LCOE formula is $[2,3]$ :

$$
\begin{aligned}
\mathrm{LCOE} & =\frac{\sum_{n=0}^{N} \frac{C_{n}}{(1+d)^{n}}}{\sum_{n=1}^{N} \frac{Q_{n} \times(1+r)^{-1}}{(1+d)^{n}}}, \\
C_{n} & =I_{n}+O_{n}+F_{n},
\end{aligned}
$$


where:

$C_{n}$ - cost of system operation in year $n$ of operation, $I_{n}$ - investment in year $n$ of operation $\left(I_{0}\right.$ - initial investment),

$F_{n}$ - cost of fuel in year $n$,

$O_{n}-$ O\&M cost in year $n$ of operation,

$Q_{n}$ - energy production in year $n$ of operation,

$d$ - discount rate,

$r$ - yearly degradation rate of the system,

$N$ - number of years of analysis (usually lifetime).

For LCOE calculations two discount rates are used [2]: nominal $\left(d_{n}\right)$, real $\left(d_{r}\right)$ and additionally inflation rate $(e)$. The relationship between those three discount rates is:

$$
\left(1+d_{n}\right)=\left(1+d_{r}\right)(1+e) .
$$

\section{Economic analysis of alternative technologies}

\subsection{Basic assumptions}

The analysis of each technology options for electricity generation is based on cash flow calculation on lifetime of the investment for each case. Selection of the discount rate depends on the dimension of the investment and the type of the investor [2]. In commercial and residential sector investments, most experts recommend to use the opportunity cost of capital [2], which is the best rate of return of the invested money. The investment in residential sector is intended to bring saving rather than gains. For this reason, a simple and good alternative for money investment is in bank deposit which brings an annual rate of return, but this option could be unreliable in case of financial turmoil.

Where the legal framework offers incentives for using renewable energies in residential applications, the financial gain is possible, but in the following analysis the incentives are not considered, because they are either locally applied or utterly uncertain on long term. In the subsequent analysis the discount rate considered is the highest interest paid by Romanian banks to the account holder, which is at $4 \%$ year.

Whether the investment in renewable energy conversion technology is only for saving purposes, or for home use of the produced energy, the taxes are not applicable. The analysis is devoted to the most common used residential energy generating technologies, both for small on-grid wind and for off-grid applications: wind, photovoltaic and diesel/ gasoline generators.

The period of analysis for LCOE calculations is 15 years which is common for wind turbines and photovoltaic systems and it is also applied for diesel/gasoline generators, just to have a common basis for comparing their viability as investment alternatives for local electricity production.

\section{Small wind turbines on-grid}

For evaluating the energy savings which can result from using different technologies for on-grid systems, the reference in analysis is the local household energy purchasing price.

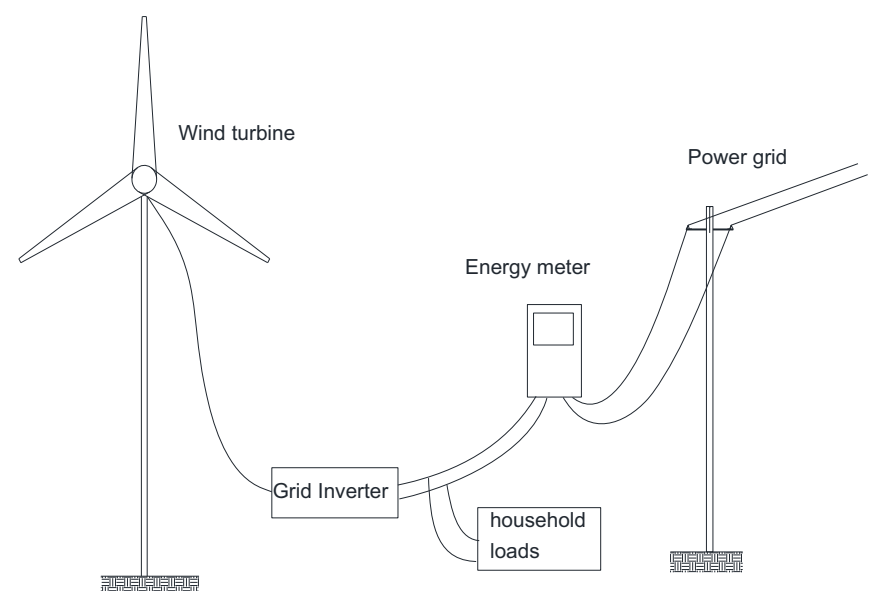

Fig. 1. Layout of on-grid wind turbine system.

The source of energy prices in EU28 is EUROSTAT [4], which are: in Romania $-0.132 € / \mathrm{kWh}$, maximum EU28 $-0.3 € / \mathrm{kWh}$ and minimum EU28 $-0.092 € / \mathrm{kWh}$.

The general layout of grid-connected small wind turbine is given in Figure 1. The small wind turbine is connected to the power grid via a dedicated inverter which maximizes the power transfer, via MPPT algorithm or predefined power curve.

A typical power curve of a $2.5 \mathrm{~kW}$ wind turbine with rated power at $12 \mathrm{~m} / \mathrm{s}$ wind speed, is given in Figure 2, which is the basis in the following analysis. For having a general approach, easily to be extrapolated, the following calculations are performed on normalized $1 \mathrm{~kW}$ wind turbine derived from the $2.5 \mathrm{~kW}$ turbine power curve, keeping the same profile of power coefficient $C_{p}$ curve. The yearly energy production computation of the wind turbine is a standard one [5].

Specific investment cost in small wind turbine systems shows large variations depending on producer, quality of the components, size, local manpower costs, and location of the installation. This specific cost ranges from 2000 to $7000 € / \mathrm{kW}$, resulting from different sources $[6,7]$. O\&M costs are variable and the data available is not quite reliable. Most sources consider the O\&M costs at $1-3 \%$ of the initial investment as reasonable [6]. In the following calculations O\&M is considered $2 \%$ year.

The LCOE family curves in Figure 3 are computed versus annual average wind speeds, at different specific investment values. On the same chart it is the household energy purchasing prices in EU as references.

The financial viability in small on-grid wind investment is in the region where LCOE curve in Figure 3, computed for a specific investment value, is lower than the household energy price at the implementation location.

Break-even point for a specific investment value is at the intersection of the respective LCOE curve with the line representing the household energy price. Beyond this point, towards higher wind speeds, the savings obtained when using small wind technology brings tax-free profit/savings on long term to the investor.

In countries where the household energy price is lower, the financial viability can be reached at smaller specific investment costs and higher annual average wind speed which limit the geographical area where the grid-connected small wind systems can be efficient. 


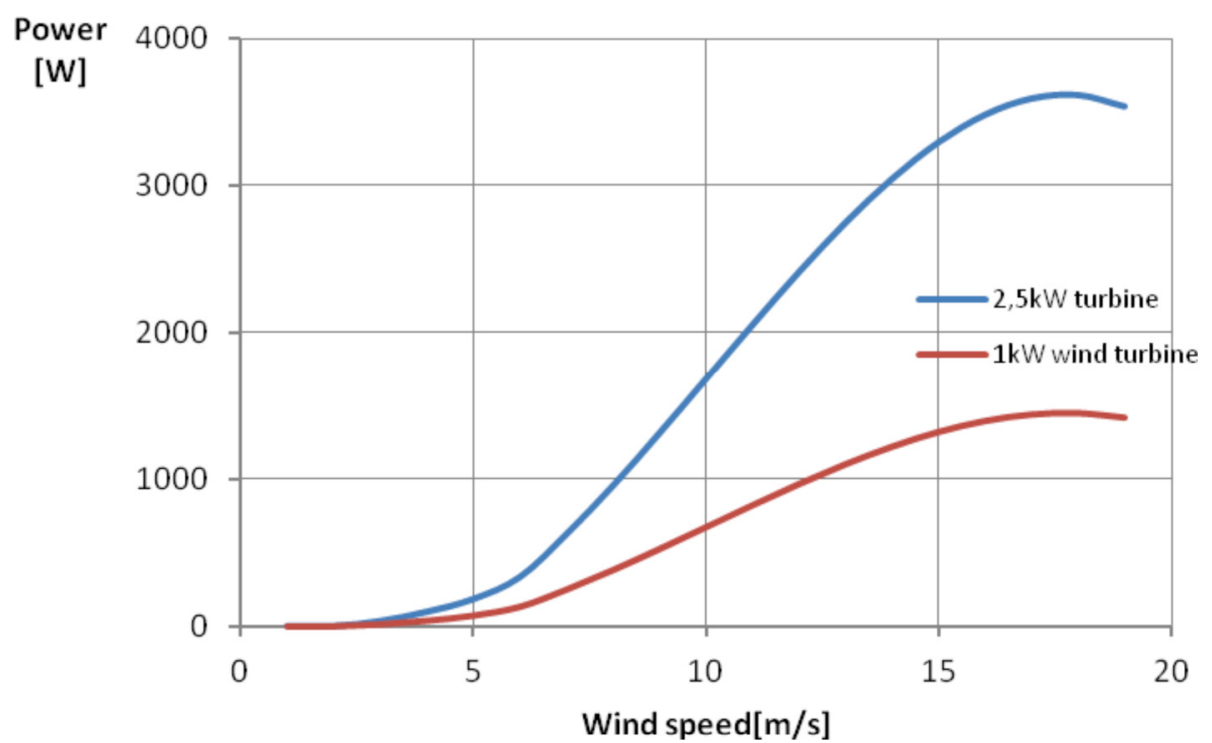

Fig. 2. Typical $2.5 \mathrm{~kW}$ wind turbine power curve and normalized power curve.

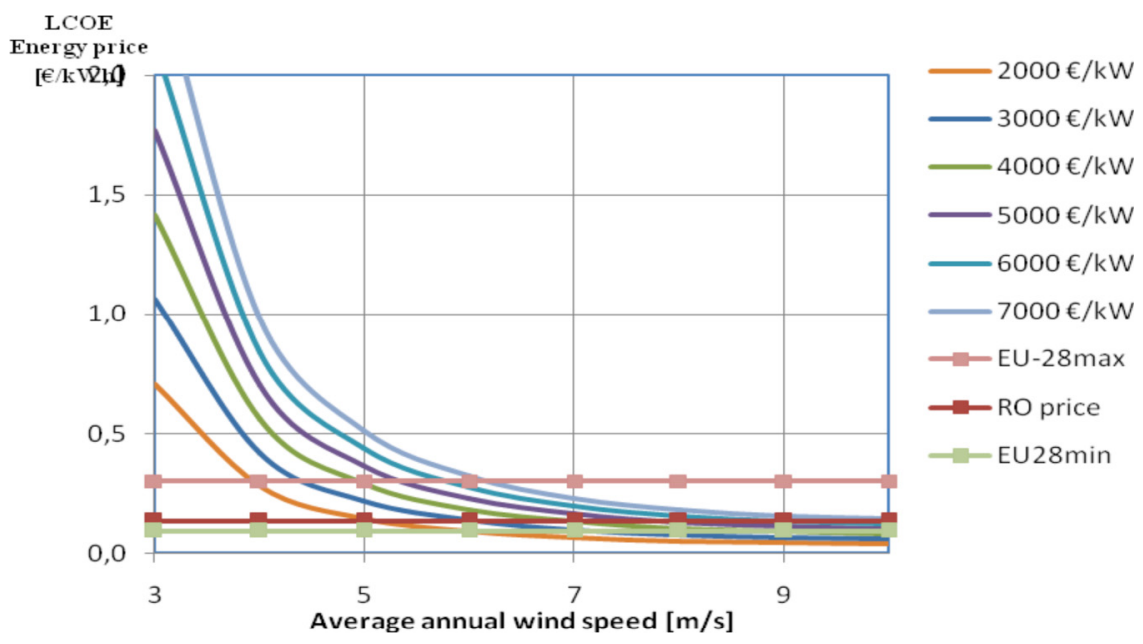

Fig. 3. LCOE for on-grid wind turbines and EU28 household energy prices.

Figure 4 is a comprehensive representation of investment viability boundaries in on-grid small wind turbines in case of different household energy prices in EU28. The money is well invested where the annual average wind speed and the specific installation price is above the boundary corresponding to the household energy price graph. Figure 4 family graphs can be used directly by a potential investor to have an immediate indication on how much can afford to spend on a residential small wind turbine system given the annual average wind speed at the specific location.

\subsection{Off-grid residential energy systems}

For off-grid residential generating systems the approach is different. In this situation the energy price is not depending on the energy market or regulations of the national authorities, as it is the Romanian case. The investor should look after the most convenient technology which can result in lowest cost of energy locally produced.
Three technologies are examined, which are, in fact, the most common solutions implemented so far: small wind turbines, PV systems and gasoline generators. In many cases, the best option is to have a hybrid system which is the combination of these three technologies.

Figure 5 is the general layout of an off-grid system. For such systems is mandatory to have a storage battery because the load profile cannot be fitted to the availability of the renewable energy sources, wind and sun. In case of diesel/gasoline generator the energy availability can be commanded by the instantaneous load, but the quality and availability of energy could suffer in some circumstances in systems without energy storage which is quite undesirable for the energy users.

Every energy source in Figure 5 is injecting energy into the battery bank, which is common for all configurations, via a dedicated power electronic adapter, specially designed for the input energy source and available on the market. The prices of these electronic adapters are quite similar or very close to each other. 


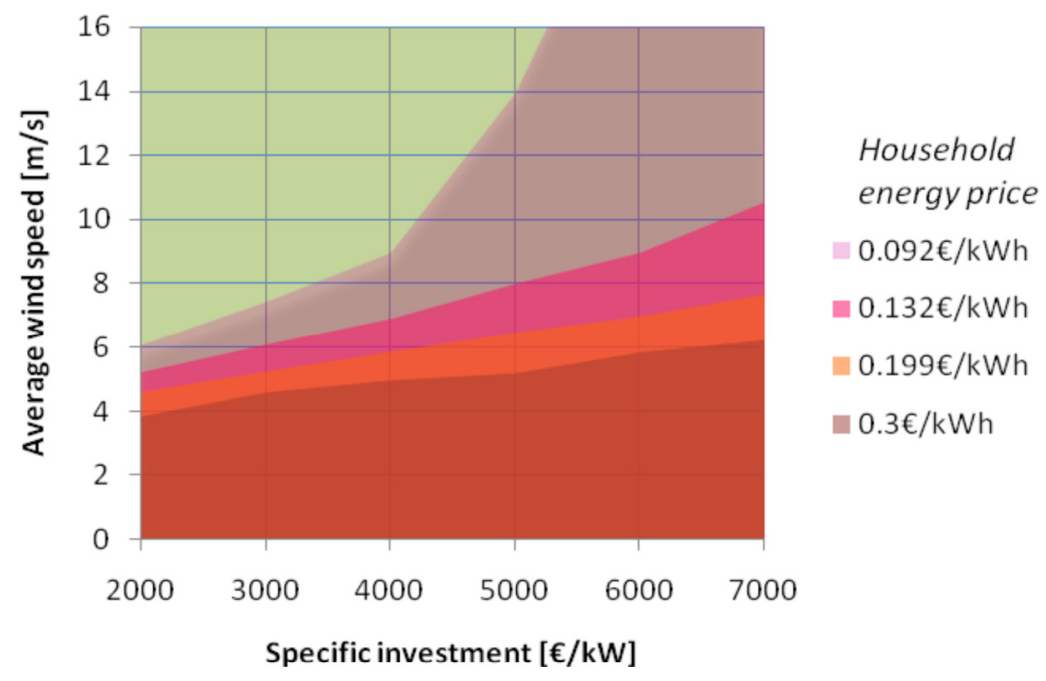

Fig. 4. Investment viability of on-grid wind turbines.

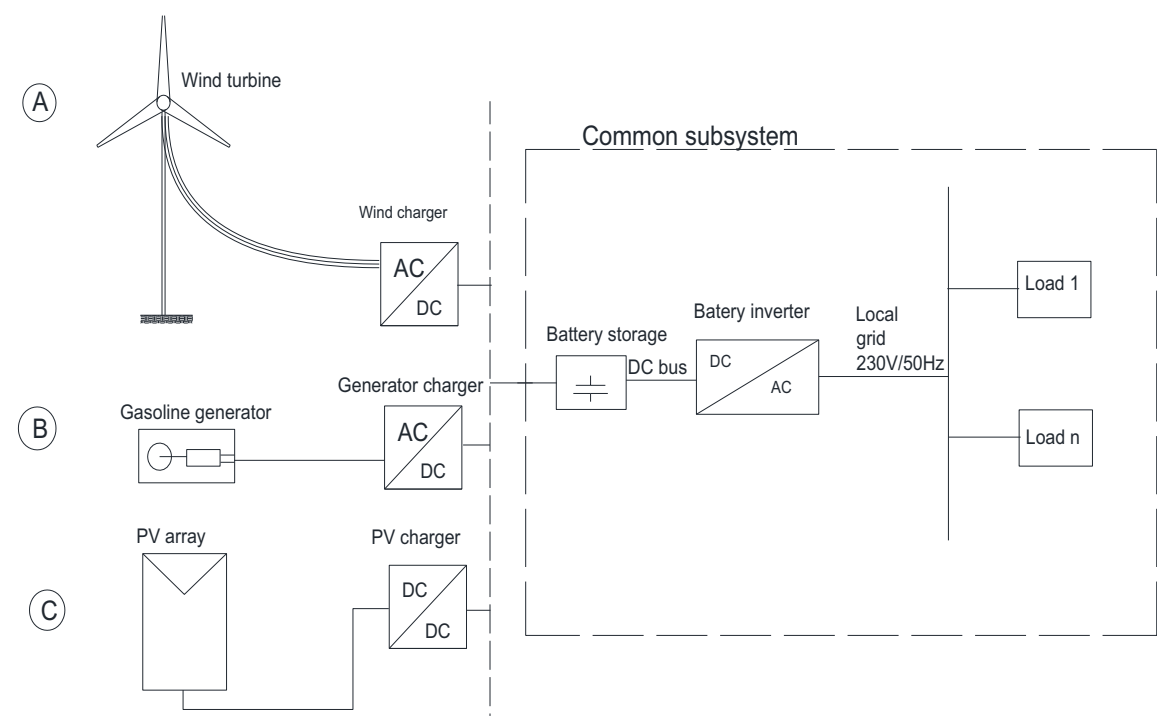

Fig. 5. Layout of a typical off-grid system.

The subsequent analysis is intended to make a comparison of technologies, and, for this purpose, each configuration is analyzed separately, as follows:

- Case A - system with small wind turbine;

- Case B - system with gasoline generator;

- Case C - Photovoltaic system.

\subsubsection{Basic assumptions}

The analysis refers only to the investment which is in the variable part of the system, see Figure 5. For comparing the lifetime energy producing costs, LCOE, the approach is different from grid-connected systems. In on-grid applications, the reference is the household energy price, but in off-grid system the reference is the energy demand by the local system loads which is in fact the purpose of the energy system.

For calculation of LCOEs for the three technologies of choice a base load of $1 \mathrm{~kW}$ is considered, which means $24 \mathrm{kWh} /$ day or $8760 \mathrm{kWh} /$ year.
Cash flows for each case are calculated for 15 years lifetime, which is valid for wind and photovoltaic technologies. But, for comparing the resulted LCOEs, the same period is applied to gasoline generators case with explanations below.

\subsubsection{Data for small wind turbine}

The investment costs in case of small wind turbine technology is the same as in case of on-grid systems since the wind turbine is the same in both situations. The only difference could be in the price of grid inverter, which can be slightly more expensive than the wind charger. But the difference in overall investment costs is quite small and the impact on computations is negligible. The size of the wind turbine in computations is varied in this case depending of the average wind speed, which can generate in all situations an average base load of $1 \mathrm{~kW}$, meaning $8760 \mathrm{kWh}$ each year. 


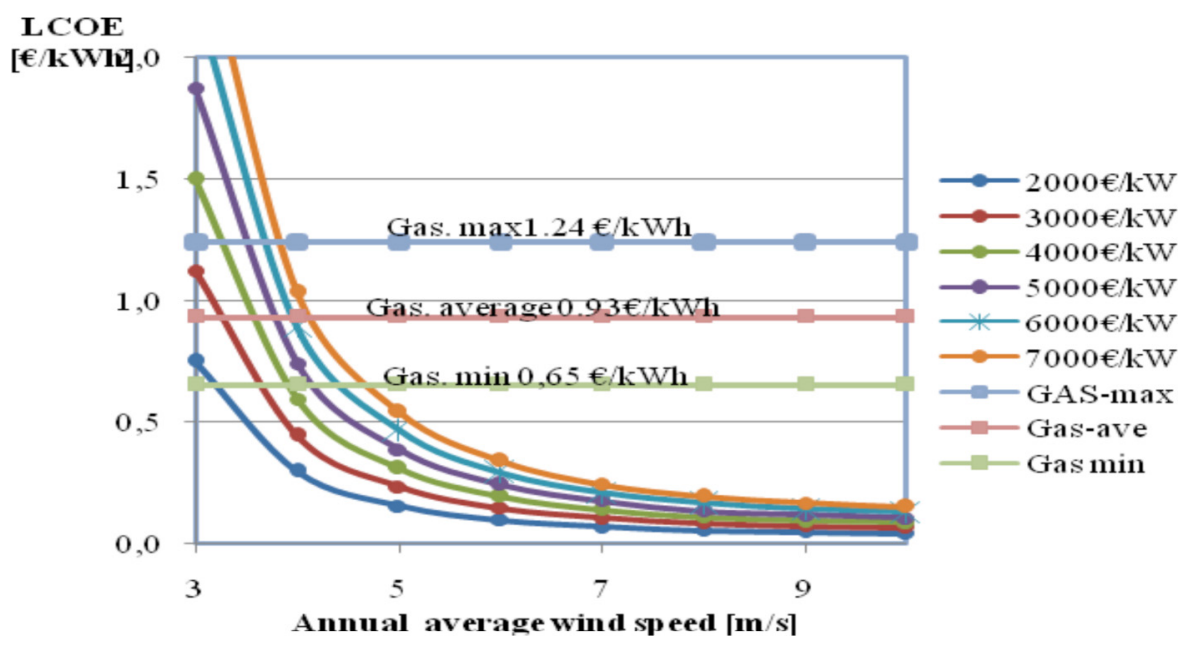

Fig. 6. LCOE for wind versus gasoline generators in off-grid systems.

\subsubsection{Data for photovoltaic systems}

In case of photovoltaic system, the investment price, including VAT, is between $1400 € / \mathrm{kWp}$ (denoted $P V$-min) and $2000 € / \mathrm{kWp}$ (denoted $P V$-max) according to market investigation on home PV systems.

The annual production of $1 \mathrm{kWp}$ of $\mathrm{PV}$ system is $1150 \mathrm{kWh} / \mathrm{kWp}$, average for Romania [8]. For providing $8760 \mathrm{kWh}$ each year, which is the energy reference for the analysis, the PV system should have $7.62 \mathrm{kWp}$ installed power (Romanian case).

Yearly degradation of PV module is considered $1 \%$, which is mostly accepted. O\&M cost estimations are variable but a reliable average figure is at $19 € / \mathrm{kWp} /$ year [9].

\subsubsection{Data for gasoline generators}

Many types of gasoline generators are available on the market showing great variations in quality, efficiency, nominal power and per $\mathrm{kW}$ price. For this study a market investigation has been performed on gasoline generators with nominal power ranging from 1 to $6.2 \mathrm{~kW}$, which are suited for household applications. During the market investigation 12 types of gasoline generators have been analyzed.

The results of the investigation are:

- Average specific price: $139.6 € / \mathrm{kW}(173.1 € / \mathrm{kW}$ including $24 \% \mathrm{VAT}$, in case of Romania);

- Fuel consumption:

- average: $0.70 \mathrm{l} / \mathrm{kWh}$ denoted $G A S$-ave,

- min: $0.48 \mathrm{l} / \mathrm{kWh}$, denoted GAS-min,

- max: 0.94 l/kWh-denoted GAS-max;

- Gasoline price: 1.30€/1 (Romania - May 2015);

- Lifetime: 5000-10,000 h (average $8000 \mathrm{~h}$-almost one year).

A gasoline generator cannot run full time for providing energy, since it requests often maintenance work and fuel consumption is different at different loads. If running $24 / 7$ the generator should be replaced every year. A practical solution is to have a $5 \mathrm{~kW}$ generator running for instance $20 \%$ of time for charging the battery running at the most efficient operation regime for producing $8760 \mathrm{kWh} /$ year energy as explained above. In the same time, the lifespan of gasoline generator can be extended to 5 years, in average, instead of one year.

\subsubsection{Results of LCOE computations}

For each of the three technologies for energy generation the specific cash flows are calculated and the results are LCOE curves versus annual average wind speed which is the sole variable in the analysis.

Figure 6 shows a comparison between LCOEs of wind technology at different specific investment costs and LCOE for gasoline generators. It is quite obvious that the gasoline technology produces energy at the highest LCOE, despite low initial investment.

Wind technology is more financially efficient than gasoline generator for wind speed beyond $4.7 \mathrm{~m} / \mathrm{s}$ whatever the fuel consumption of the gasoline generators is.

Figure 7 shows a comparison between LCOEs for small wind and PV technology in off-grid applications. The energy produced by wind technology gives better results for wind speeds above $5.5 \mathrm{~m} / \mathrm{s}$ at low specific investment cost. For lower wind speeds, PV technology is a better option for both on-grid and off-grid energy systems. The results of LCOE computed for industrial scale PV systems [10], are in the same range as the results of this analysis.

\section{LCOE analysis in case of subsidies}

The above analysis can be easily extended in case of subsidies for renewable energy production, either as premium price received for energy production, such as feed-in tariff, or in case of investment aid. In both cases the subsidies should be included in lifetime cash flow.

In case of subsidies for produced energy, e.g. expressed in $€ / \mathrm{kWh}$, it is a yearly income, $R_{n}$, for the user of renewable energy system. Cost of system operation in year $n, C_{n}$, is computed as in (4).

$$
C_{n}=I_{n}+O_{n}+F_{n}-R_{n} .
$$




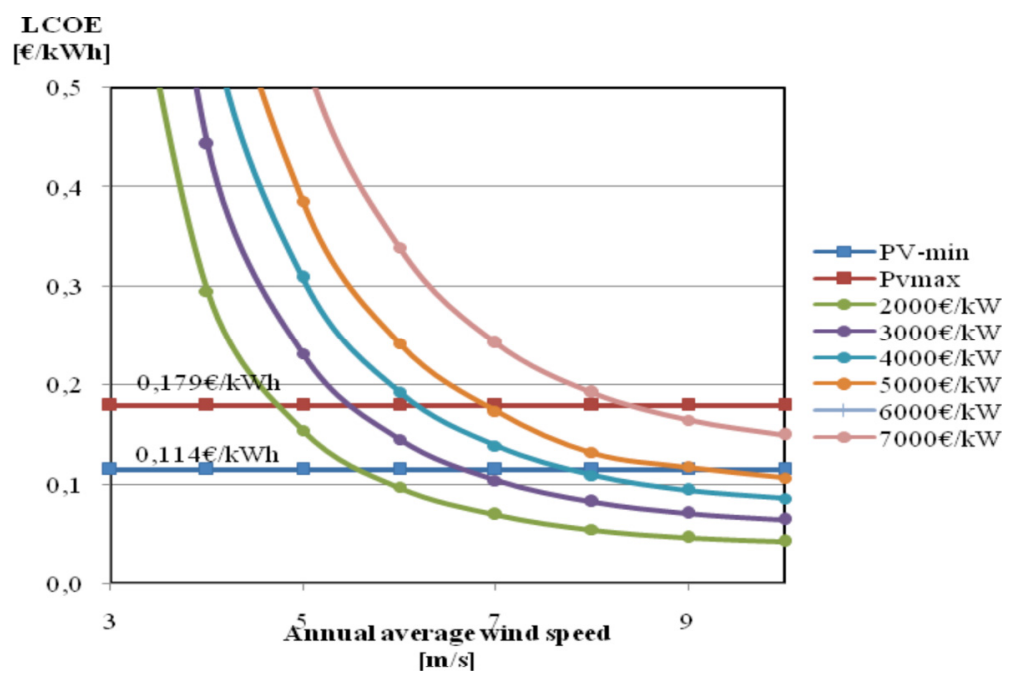

Fig. 7. LCOE for off-grid wind and PV technologies.

Whether the case of investment aid is, $I_{n}$ in formula (4) should be only the net amount paid by the investor for installing the system.

\section{Conclusions}

The LCOE computed for different technology options is a comprehensive value for deciding whether an investment in small wind residential system is viable or not at one location of the investment, or for selecting which type of technology is better suited for specific wind and solar resources.

In case of on-grid systems, a good investment at one location is when computed LCOEs for alternative technologies are equal or less the household energy price on the market. In case of off-grid generating systems, LCOE computed for every alternative technologies helps investor for selecting the technology which produces energy at the lowest cost.

The analysis defines the boundaries within which an investment in renewable residential energy generating system can give positive financial results when is operating over a period, commonly the lifetime.

All the results presented in the paper can be used directly knowing local wind and solar resources and household energy price for deciding what the upper limit of specific investment cost of alternative options is which are financially viable or selecting the appropriate energy generation technology.
This paper was elaborated in the framework of the Programme Partnership in prioritary domains - PNII, financed by MEN UEFISCDI, project No. 41/2014.

\section{References}

1. S. Ganger, J. Pitteloud, Small Wind World Report 2014, World Wind Energy Association (2014)

2. W. Short, D.J. Packey, T. Holt, A manual for the economic evaluation of energy efficiency and renewable energy technologies, March 1995, NREL/TP-462-5173 (1995)

3. K. Cory, P. Schwabe, Wind levelized cost of energy: a comparison of technical and financing input variables, Technical Report, NREL/TP-6A2-46671 (2009)

4. EUROSTAT, Half-yearly electricity and gas prices, 2011-13

5. IEC 61400-12-1, Wind turbines. Power performance measurement of electricity producing wind turbines

6. http://www.wind-power-program.com/turbine economics. htm

7. World Wind Energy Association, Small Wind World Report (2013)

8. http://re.jrc.ec.europa.eu/pvgis/apps4/pvest.php

9. NREL, Distributed generation renewable energy estimate of costs (2013)

10. C. Kost, J.N. Mayer, J. Thomsen, N. Hartmann, C. Senkpiel, S. Philipps, S. Nold, S. Lude, N. Saad, T. Schlegl, Levelized cost of electricity renewable energy technologies, Fraunhofer Institute for Solar Energy Systems (2013)

Cite this article as: Mihail Predescu, Economic evaluation of small wind turbines and hybrid systems for residential use, Renew. Energy Environ. Sustain. 1, 33 (2016) 